\title{
The Search, Discovery, and Survey of a World War II Japanese Type "A" Midget Submarine
}

\author{
John C. Wiltshire, Terry Kerby \\ University of Hawaii • Honolulu, Hawaii USA
}

\author{
Algis N. Kalvaitis \\ National Oceanic and Atmospheric Administration. Silver Spring, Maryland USA
}

\section{Introduction}

This paper describes the search, discovery and inspection of a World War II (WW II)-era Japanese midget submarine discovered in waters off Pearl Harbor, Hawaii. This discovery was made on August 28, 2002, by the Pisces IV and Pisces V, two deep-diving submersibles operated by personnel from the Hawaii Undersea Research Laboratory (HURL), one of six research centers comprising the National Oceanic and Atmospheric Administration's (NOAA) National Undersea Research Program (NURP). This Japanese midget submarine was the first vessel sunk in the attack on Pearl Harbor, December 7, 1941, and it is evidence of the first shot of the war in the Pacific. The sunken midget sub was located during the last of a series of test and training dives conducted annually in the military debris fields off Pearl Harbor. This midget submarine find has been described as the most significant modern marine archeological find ever in the Pacific, second only to the finding of the Titanic in the Atlantic.

The Japanese midget submarine was one of five attached to five I-class mother submarines and launched in the predawn hours before the aerial attack, within a few miles of Pearl Harbor. These midget submarines had orders to infiltrate the Pearl Harbor Naval Base and sink capital ships once the air raid began. Each submarine carried a crew of two. The submarines were battery powered, $24 \mathrm{~m}$ long, $2 \mathrm{~m}$ diameter and displaced nearly $42,000 \mathrm{~kg}$ submerged. They carried two torpedoes and a scuttling charge to avoid capture. Although experimental in design, they were very advanced for their time. For short periods, they could run at $10 \mathrm{~m} / \mathrm{s}$ (20 kts). All five of the submarines comprising the advanced attack force were sunk or captured. The type A midget submarines had a series of basic design problems including trim and ballast control as well as battery life and battery monitoring. The Japanese midget submarines, although believed at the time to be a potent secret weapon, in actual fact, were never highly effective. So far, four of the five original midget submarines attacking Pearl Harbor have been found.

The discovery of the midget submarine confirms the account radioed to naval command at Pearl Harbor at 6:45 am on December 7, 1941. A Japanese submarine was shot through the conning tower and then depth charged trying to enter Pearl Harbor behind a cargo ship. There were standing U.S. orders to attack any submarine, inside a defensive sea area, that was not surfaced and escorted by a U.S. Naval vessel. The crew of the attacking USS Ward, an older style four-stack destroyer, fired the fatal shot from its four-inch side gun. Unfortunately, the Naval command in Pearl Harbor ignored the Ward's report and the aerial attack began at 8 a.m. At the Pearl Harbor investigation, some question was made of the accuracy of the Ward's report. The Ward itself was sunk by a kamikaze strike, ironically on December 7, 1944, exactly three years after the Pearl Harbor attack.

\section{Search for the Midget Submarine}

Numerous searches have been undertaken ever since the submarine was reported sunk. The most recent of these involved HURL, which conducted towed side scan sonar surveys of the debris fields off Pearl Harbor in March 2002. This was also a test of a system for fish habitat surveys. This system could be tested most efficiently by comparing known targets located by the Pisces research submersibles to images mapped by the side scan sonar fish. It was during one of these towfish passes that a very promising target was noted. This target would be identified as part of the HURL test and training dives scheduled in August 2002 prior to the start of the science season. The dual submersible test dives would serve to define the oper- 


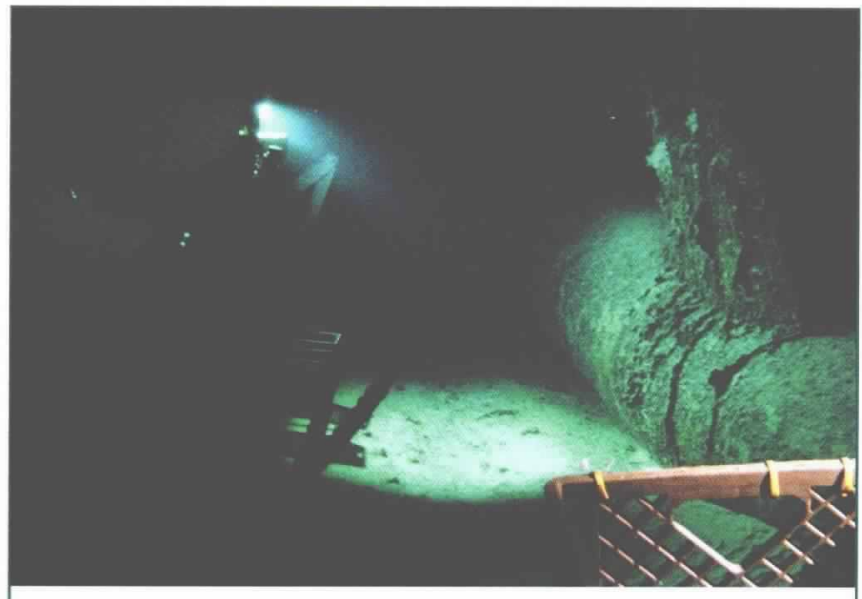

Figure 1. The Hawaii Undersea Research Laboratory's submersible PISCES $V$ at the moment of discovery of the type A Japanese midget submarine which was sunk off the mouth of Pearl Harbor on December 7, 1941.

ational parameters of any future two-submersible dives and also offer an opportunity to conduct tracking exercises to test the ability of one submersible to locate the other in the event of an emergency.

At the end of World War II, obsolete war materiel was dumped in 300-1,000 $\mathrm{m}$ of water several miles off Pearl Harbor. These have included landing craft, tanks, old aircraft, trucks, barges, small ships and fuel tanks. There are approximately 1,000 significant sonar targets in the area. Sorting through these various targets to identify the most promising to inspect as a submersible pilot training exercise has been a formidable task over many years. The Japanese midget submarine, although giving a very clear return on the side scan survey, was interspersed with other debris on the bottom complicating the search efforts.

\section{Environmental Conditions at the Site}

Hawaiian surface currents are very complex. These are the result of large-scale ocean currents, coastal tidal currents, wind currents and waves, and the coastal topography. Although the flow of the large North Pacific Equatorial Current is generally westward, it is altered by the local topography and has less of a westward drift during the winter. The generalized surface circulation outside of Pearl Harbor where the Japanese submarine was shot and sunk varies with the tidal cycle. The water moves slightly shoreward during flood tide while the ebb circulation moves eastward under general trade wind conditions. The tidal current speed varies greatly and can be over one knot. This area is in the lee of the trade winds, so there are minimal trade wind effects. The bottom currents are westward but the magnitude and variability are unknown.

According to reports during the morning of December 7, 1941, the sunrise was spectacular and sailors were admiring the heavens when someone first

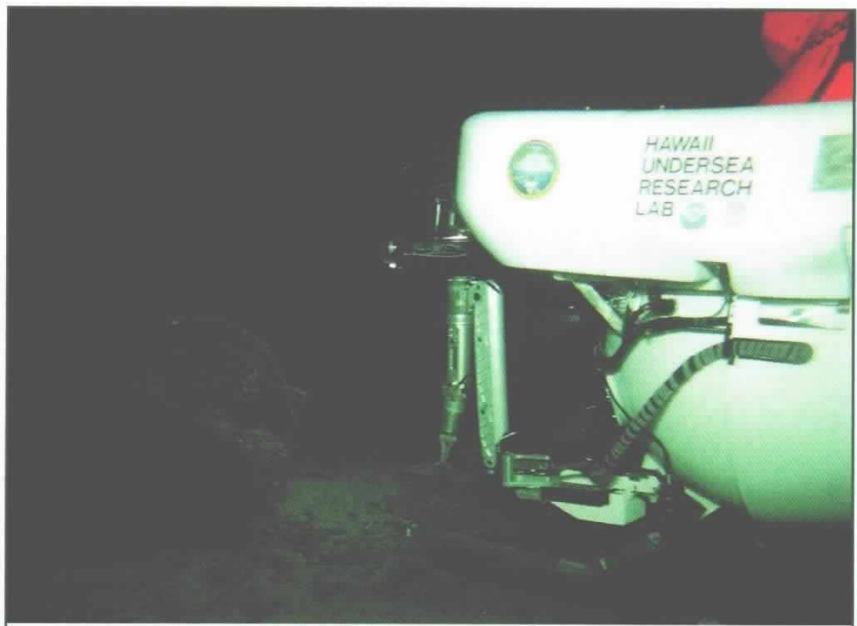

Figure 2. The Hawaii Undersea Research Laboratory's Submersible PISCES IV beside the propellers of the Japanese midget submarine.

spotted the broaching conning tower of a submarine. The seas were quite rough at nearby locations. For example, approximately several miles southwest of Barbers Point, even at $25 \mathrm{~m}$ depths, one of the " $\mathrm{I}$ " class mother submarines was rolling in place. It must have been particularly difficult for the $24 \mathrm{~m}$ long midget submarines to maintain depth control under those conditions. This may explain why the conning tower was exposed.

\section{Pisces IV and Pisces V Submersible Dives}

The first time both HURL submersibles dove together was on August 24, 2002. The purpose of those dives was to allow the $R / V$ Kaimikai-o-Kanaloa shipboard tracking team to become familiar with tracking and communicating with two targets. The Pisces IV successfully located the Pisces V with the pinger receiver system as part of the tracking rescue exercise. The subs then conducted a search for the primary target identified in the March 2002 side scan survey. The submersibles conducted an extensive search in the area of the prime contact trying to determine the geographical error of the mapping information. After crisscrossing the area using a large area small-scale chart, the submersibles moved to the west where they discovered the wreckage of an unknown $55 \mathrm{~m}$ patrol ship. The submersibles conducted a survey of the ship before leaving the bottom. A search of the area did not produce a target that could be identified as the primary target.

The submersibles conducted Dive \#2 on August 26. The primary mission was to conduct a tracking exercise with the Pisces V locating the Pisces IV. The submersibles would then split up, and each one would locate and identify two targets. This would allow the surface tracking team the exercise of tracking and communicating with two subs running in different directions. This exercise would establish parameters for distance limits for maintaining safe control of two 
submersibles operating in different areas. However, the Pisces V had a battery box alarm as soon as it reached the bottom and had to abort the dive. The Pisces IV continued the mission and identified three of the four targets to add more information to the area survey and verify bottom mapping information.

The third training exercise, Dive \#3, on August 28 would have an additional passenger in the Pisces IV. A representative from the NURP office would ride in Pisces IV to observe the safety exercise with the submersibles. For the exercise, Pisces IV would remain stationary on the bottom and Pisces V would attempt to locate it and cut a line tied across the front of Pisces IV's collecting basket. The submersibles would then attempt to once again locate and identify the primary target. If it wasn't the midget sub, the exercise would be to proceed north to locate and identify target \#4. The subs were unable to split up because of communications problems with Pisces V. The submersibles would be searching the area using a large-scale small area chart so they could better locate the target and determine the geographic error of the mapping information. The primary target was located after noon. It was the Japanese midget submarine.

\section{The Discovery}

The first thing to come into view for the Pisces V's crew was the bow of the Japanese midget submarine with the two torpedoes still in place. This was initial evidence that the submarine could be the one sunk by the USS Ward. The crews of both submersibles noted that the submarine was intact and in seemingly good condition. The submarine is upright with a slight port list and is facing to the east. It shows no sign of impact damage with the bottom or depth charge damage to the hull. The submersibles positioned themselves to conduct a detailed visual inspection and coordinated video survey of the midget sub.

\section{Condition of Submarine}

The following paragraphs document the condition of the submarine. The bow section of the midget submarine shows the two torpedoes still in place. The port side of the conning tower appears undamaged from the action with the USS Ward. Marine growth and rust deposits cover much of the conning tower. There is one elongated hole, which appears to be the step in the sail for accessing the hatch in the conning tower. There is a small grouping of holes at the lower mid-section of the port side which may be rust holes, but there does not appear to be any advanced rust corrosion as there is on a midget submarine conning tower that HURL discovered in September 2000.

Eyewitness accounts from the USS Ward reported that the first shot from the bow gun passed over the top of the conning tower and splashed on the other side. The after-deck gun made a solid hit at the base of the conning tower on the starboard side. The Pisces V crew

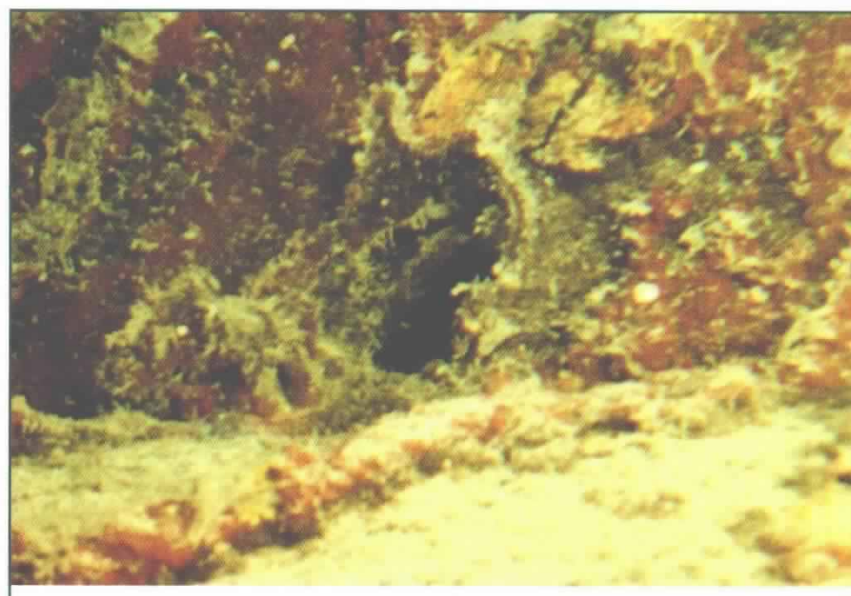

Figure 3. The starboard side of the Japanese midget submarine showing the shell hole from the four inch side gun of the USS Ward. The shell impacted at the point where the conning tower joins the pressure hull of the submarine. The shell did not explode but merely penetrated the pressure hull.

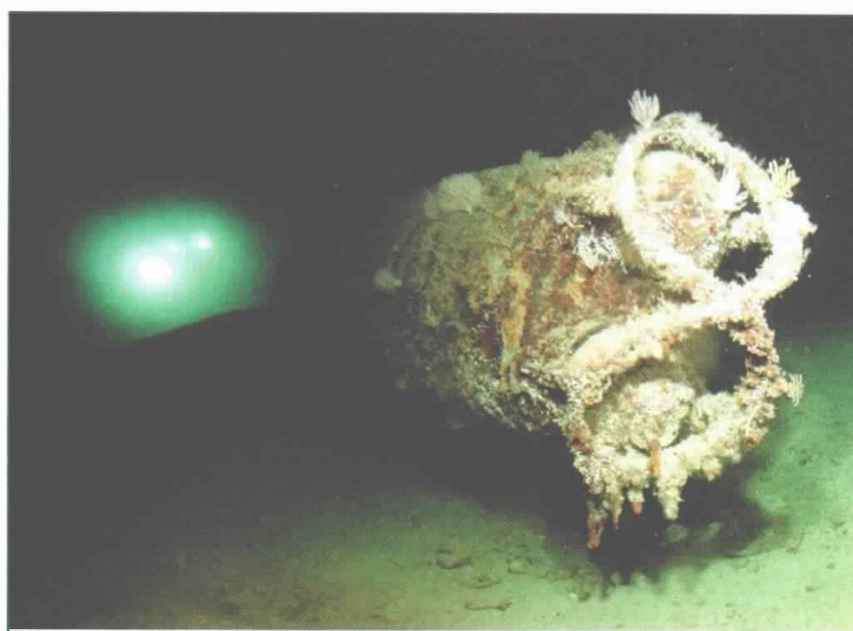

Figure 4. The bow of the midget submarine showing the two torpedoes still in tact, unfired with the torpedo tube covers still in place. In front of the torpedo tubes is a figure eight torpedo guard which also served as a line cutter.

verified that the shot did not pass through the conning tower. Eyewitness accounts report that they did not see any explosion from the shot that hit the starboard side of the conning tower. There does not appear to be any distortion in the hull or conning tower that would be caused by a detonation of the shot that entered the starboard side. The small grouping of holes around the elongated hole appears to have been caused by something entering from the port side. A closer inspection will have to be made to determine if these are puncture holes or rust holes.

The periscope is in the up position and is fouled with lines. The line streaming off the top of the 


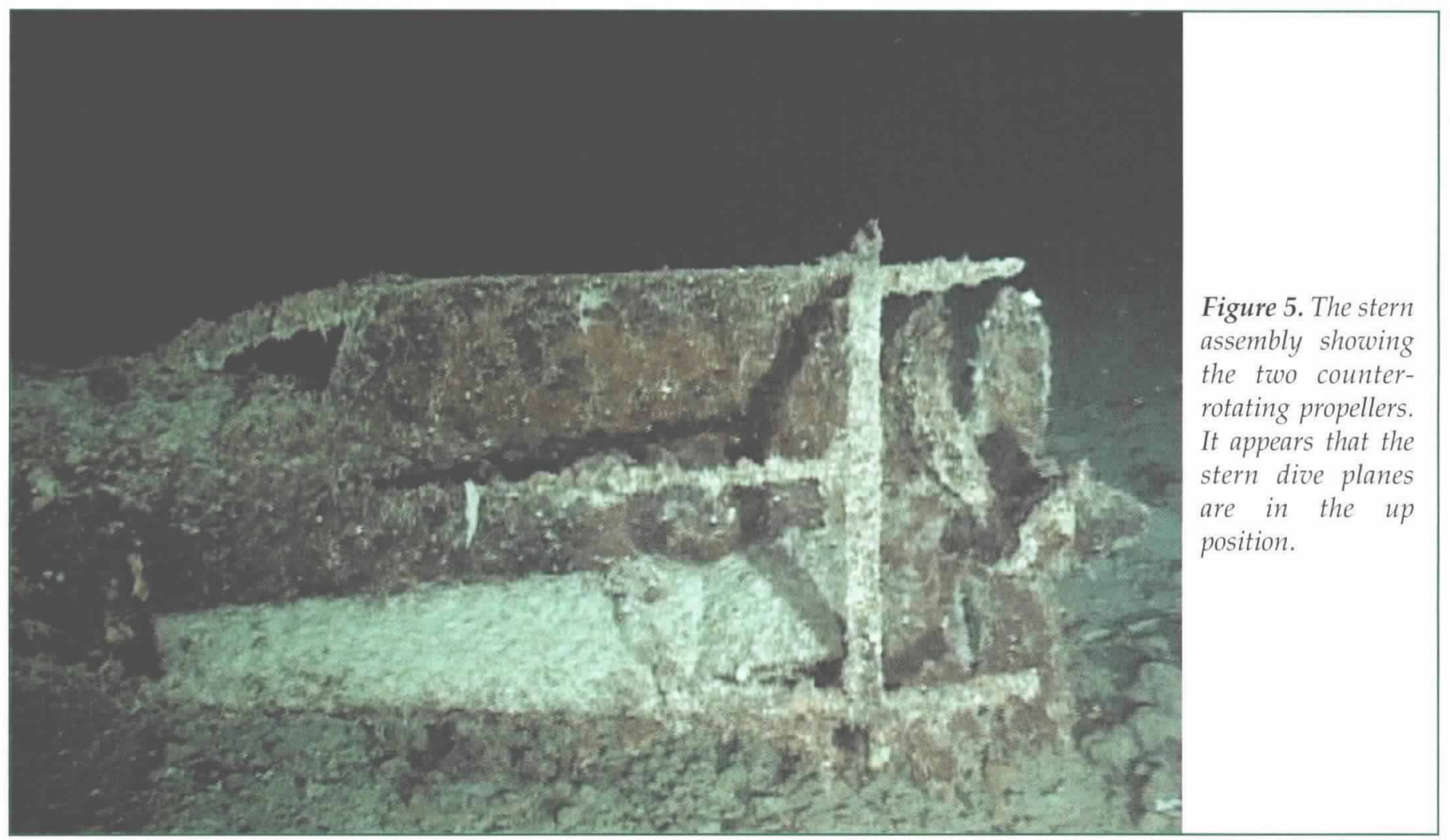

periscope made a handy current indicator or "wind sock" for the survey flights along the hull with the Pisces subs. The rope-guard rails around the access hatch at the top of the sail are intact and undistorted. The forward tensioning pulley is in place, but the forward and after rope guards are down. A closer examination of the digital image of the top of the periscope looks as though it was directed to the port quarter of the submarine. The lines fouled around the top of the periscope make it difficult to see.

There is a sandy berm built up against the starboard side of the hull at the conning tower. This enabled the Pisces IV to get close enough to give the crew a level view at the base of the conning tower. Eyewitness accounts from the Ward stated that they saw the second shot from the \#3 deck gun hit the submarine at the base of the conning tower. The crew of the Pisces IV discovered a hole at the base of the conning tower exactly where the Ward's crew claimed it would be located.

The Pisces IV and Pisces V maintained position on both sides of the conning tower during the initial survey. There was no light detected coming through the conning tower at any time. The conning tower on both sides of the submarine appears to have escaped the ravages of advanced corrosion. Most other vehicles, landing craft, and aircraft discovered in the defensive sea area are in advanced stages of decomposition. The starboard side of the conning tower is covered with marine growth and what appear to be ridges of biofouling. There is some of this growth around the hole at the base of the conning tower.

Initially it appeared as though the metal had been blown out from the port side of the conning tower. A closer examination of this extruded lip around the hole shows that it is most likely marine growth. The Pisces IV was able to obtain a close-up image of the hole in the starboard side of the conning tower. This is a clean round hole caused by a projectile that entered from the starboard side. The edge of the hole with torn metal is visible inside the ridge of marine growth. Closer inspection of the hole shows that a projectile may have entered the conning tower between the access trunk and the periscope assembly. From the height that the shell was fired, it is most likely that the projectile went through the base of the conning tower and pressure hull and into the command compartment at the position of the periscope station.

Eyewitness accounts reported that they did not see the shell detonate. There is no distortion in the hull on the port or starboard side that would indicate that the shell exploded when it entered the submarine. If the shell passed through the hull, it would have passed through the lower port side. There is no hole evident on the lower port side of the hull, but there is a sandy berm built up on the port side of the hull aft of the conning tower that could be covering a hole. A closer inspection of the lower port side of the hull should be made to see if there is any sign of an exit hole. It may be possible that the shell did not detonate but splintered when it entered the starboard side of the conning tower and is still inside the submarine. 
There is little bottom growth on the hull, and the currents have scoured a depression under the bow back to the conning tower. The bow section is unsupported which indicates that the seam where the bow is joined to the mid-section is still sound. There is a depression under the bow scoured by the current. The submarine is facing eastward in an almost true east-west orientation. The predominant current is out of the east. There is no wash boarding on the hull from depth-charge damage.

At first it was assumed that the sand moves in and out and helps to support the weight of the bow. It was later observed that a sponge (Regatella sp.) was growing under the starboard side hull about $4 \mathrm{~m}$ back from the bow. If the sand moved in and out, this sponge would not be there, indicating that the depression under the bow and stern has been there for some time. This is further testament that the joint between the bow section and mid section is solid.

The submarine is in a slight bow-up position. The area at the bow is $1.5 \mathrm{~m}$ higher than the stern. Two $6 \mathrm{~m}$ long torpedoes were contained in the tubes in this section. The torpedoes were fired by compressed air, and each torpedo reportedly carried about $360 \mathrm{~kg}$ of explosives. There is no damage or distortion to the torpedo guards, evidence that the submarine did not impact the bottom bow first and may have landed flat on the keel when it struck the bottom. The torpedo guards are made from steel flat bar material configured in a figure eight (8) design around the torpedoes. These guards were designed to serve as rope cutters. The torpedoes themselves are not visible since the torpedo covers are in place. These covers do not appear to be corroded into the tube.

The midget subs were equipped with cables that ran from the top of the conning tower fore and aft, which provided protection from fouling in lines and aided in getting under submarine nets. With the radio antennae and periscope retracted, lines or cables would conceivably be guided by the rope guards over the conning tower and down over the stern. The after cable guard has disconnected at the conning tower and is lying on the upper hull. It is still connected at the stern. The forward end of the cable is lying down the port side of the hull aft of the conning tower. The forward cable guard is attached at the bow but appears to have broken away and is not visible on the hull. The turnbuckle assembly that held the forward cable through the tensioning pulley is still in place at the leading edge of the conning tower.

The hull section aft of the conning tower shows no signs of distortion or damage from depth-charging or impact with the bottom. There is a sand buildup aft of the conning tower, but the area forward of the stern planes is scoured clean under the hull for about $4.5 \mathrm{~m}$. The stern assembly is resting on solid bottom. There are more sponges (Regrdrella sp.) growing under the hull indicating that the sand has not built up under the stern for some time.
The stern assembly shows no signs of impact damage with the bottom. The lower port section of the prop-guard band is missing and appears to be lying on the bottom. The counter-rotating screws are undamaged. The stern planes are in the up position. It appears as though the rudder is slightly to starboard but a closer inspection is needed for confirmation.

The midget submarine is in amazingly good condition considering where it has been resting for the last 61 years. Debris have been dumped all around it including a $55 \mathrm{~m}$ ship that is just a few hundred meters from the submarine. Other seafloor debris includes airplane parts, a large diameter bundle of cable, lines and numerous drop tanks nearby. The wreck of the Japanese midget submarine needs to be protected if it is to survive intact and undamaged. It would be a tragedy to have the midget submarine destroyed by a supertanker dragging its anchor.

\section{Findings}

The Japanese midget submarine was found in 300)$400 \mathrm{~m}$ of water several miles off the mouth of Pearl Harbor. Since it is classed as a military gravesite and we are awaiting response from the Japanese government, the exact location has not been disclosed. The submarine has no apparent depth charge damage but does have shell damage. The starboard side of the conning tower shows a hole from the $10 \mathrm{~cm}$ (4-inch) shell fired by the side gun on the Ward as the ship steamed past. Apparently, this shell did not explode on impact as the midget sub conning tower is clearly still in place. While four depth charges were dropped directly on the midget as the Ward passed by, the charges were set to go off at a depth of $30 \mathrm{~m}$ and the submarine was at the surface. The pressure wave created by the four depth charges was sufficient to fully lift the $42,000 \mathrm{~kg}, 24 \mathrm{~m}$ midget submarine out of the water, but did no visible structural damage. The midget submarine likely sank from flooding through the $10 \mathrm{~cm}$ (4-inch) shell hole. It apparently sank relatively quickly as it did not drift far from the site where it was hit and sank in a horizontal orientation.

\section{Unanswered Questions}

A number of questions still remain over this submarine, which was the first casualty in the war between the U.S. and Japan. Can and should it ever be raised, perhaps to join the USS Missouri forming the bookends for the Pacific war, that is, the first shot and the final surrender? Why did the Naval command at Pearl Harbor apparently ignore a confirmed enemy sinking right off its harbor mouth? Why did the Japanese put so much faith in the five midget submarines that they were allowed to lead the Pearl Harbor attack? After all five of the attacking midget submarines were lost in their first engagement and shown to be ineffective, why did the Japanese Imperial 
Navy continue to build hundreds of midget submarines, most of which were never used?

\section{Midget Submarine: Recovery or a Marine Protected Area?}

At this time it is unclear if the submarine will be raised or if its resting site will become a marine protected area. It would be technically feasible, although difficult and expensive, to raise the submarine. Recent efforts have raised the sunken Russian submarine Kursk in arctic waters off northern Russia as well as the partial raising of the sunken Japanese fisheries training vessel Ehime Maru off Hawaii (see related article, this issue). Both of these efforts were more complicated and involved larger vessels than the Japanese midget submarine. The Kursk salvage involved a nuclear reactor and live and damaged torpedoes. Complications involved in raising this Japanese midget submarine include the two torpedoes and the scuttling charge as well as the necessity of maintaining structural integrity on a possibly damaged hull. Initial speculation on a salvage plan has focused on making the midget submarine close to neutrally buoyant either by pumping compressed air or foam into the hull through the shot hole. The midget submarine could then be gently nudged onto a $30 \mathrm{~m}$ long pallet and secured. The pallet would then be carefully lifted and towed to shallower, protected waters where divers could arrange a lift to the surface under optimal conditions.

However, the preferred U.S. policy for an intact well-preserved historic shipwreck like this would be to let it continue to be preserved and protected where it came to rest and to permit non-intrusive research as deemed appropriate. This is a precautionary approach to the management of our underwater cultural heritage that is followed unless it is determined that the public interest would be better served through intrusive research and recovery or salvage conducted in a scientific manner to preserve the site information that would be destroyed.

\section{The Location of the Submarine and Governmental Considerations}

This article does not identify the location of the submarine other than it is somewhere in the general area of Pearl Harbor. The precise location is not being disclosed at this time to protect the integrity of the submarine and insure its respectful treatment as a gravesite until a legal regime is in place to address resource protection and management issues. This submarine is significant in that it is direct evidence of the start of World War II in the Pacific. As such the submarine is a very significant historic resource that may be eligible for the National Register or perhaps National Landmark status. NOAA and other U.S. government agencies, such as the Department of Interior's National Park Service, would like to see the site preserved. The
Japanese government was informed of the discovery in a meeting at the Department of State on September 19, 2002 , when they were given a copy of a videotape documenting the August 28, 2002, finding of the submarine. At this time, the United States awaits a response from the Japanese government, and NOAA is working with the Department of Justice to decide ownership and stewardship issues.

\section{Future}

Long before any decision or plans can be formulated on the submarine's future, the site will need to be thoroughly photographed and surveyed. If permitted, a non-destructive endoscopic technique, such as that used to explore the interior of the submerged wreck of the USS Arizona at Pearl Harbor, might be used to explore the interior of the Japanese midget submarine through the shell hole. As the shell hole is quite small, this may prove to be operationally impossible. Further research at the site will certainly clarify the submarine's condition and provide valuable information for future groups contemplating raising the midget submarine. In all cases, future exploration must proceed with the greatest respect and care for this submerged wreck, recognizing it as a war gravesite likely containing the remains of the two Japanese crew.

\section{Acknowledgements}

The discovery was very much a team effort. The authors are grateful to the support and contributions by the discovery team on the Pisces submersibles. These include Chris Kelley, the HURL biologist, who conducted the side scan survey of the search site in March 2002; Chuck Holloway, who skillfully piloted the Pisces V; Collin Wollerman, pilot trainee who provided valuable assistance in the Pisces IV; and Rachel Shackelford, the HURL data manager, responsible for the video systems. In addition, the topside submersible team including Dr. John Smith, Dr. Dan Greeson, Max Cremer, Tym Catterson and Steve Price, who provided technical and logistics support during the search and discovery dives. We also acknowledge the support of Captain Ross Barnes and the crew of the R/V Kaimikaio-Kanaloa. This work was funded by Grant \# NA16RU1333 from NOAA's NURP.

\section{Related Materials}

Burlingame, B., 1992: Advance Force Pearl Harbor. Naval Institute Press, Annapolis, MD, $481 \mathrm{pp}$.

Delgado, J., 1988: Japanese Midget Submarine HA-19 National Historic Landmark Study. National Park Service, Washington, D.C. 8pp.

Haraguchi, P., 1983: Weather in Hawaiian Waters. Y's Printing and Graphics, Honolulu, HI, 99 pp.

Miller, D., 2002: The Illustrated Directory of Submarines in the World. Salamander Books, London, 480pp. 